\title{
EMPREGO DE ETANOL COMO ALTERNATIVA PARA A SÍNTESE DE ZSM-5
}

\author{
J. K. ALBIERO ${ }^{1}$, M. SCHWAAB ${ }^{1}$, E. BARBOSA-COUTINHO ${ }^{2}$ e F. de CASTILHOS ${ }^{1}$ \\ ${ }^{1}$ Universidade Federal de Santa Maria, Departamento de Engenharia Química, Centro de Tecnologia \\ ${ }^{2}$ Universidade Federal do Rio Grande do Sul, Departamento de Físico-Química, Instituto de Química \\ E-mail para contato: jalusaalbiero@gmail.com
}

RESUMO - Zeólitas do tipo ZSM-5 são aluminossilicatos de ampla aplicação industrial por sua atividade catalítica, devido à sua elevada acidez associada à excelente estabilidade térmica. Neste trabalho, propõem-se a síntese deste material utilizando cristais de ZSM-5 como sementes e etanol, em substituição aos usuais direcionadores de estrutura, como bases orgânicas nitrogenadas. A síntese foi realizada pelo método hidrotérmico, tendo como fonte de sílica, cinza de casca de arroz, e como fonte de alumínio, caulim. As sementes foram sintetizadas pelo método convencional e utilizadas de forma combinada com etanol durante a síntese das zeólitas. Esta combinação em diferentes proporções resultou na formação de ZSM-5 de alta cristalinidade, caracterizada por DRX, BET e FTIR. O emprego de sementes ou etanol individualmente não foi suficiente para a formação desta zeólita. Este resultado evidencia que direcionadores de estrutura nitrogenados podem ser satisfatoriamente substituídos.

\section{INTRODUÇÃO}

A ZSM-5 é uma zeólita do tipo pentasil, cuja estrutura porosa formada por canais se baseia em

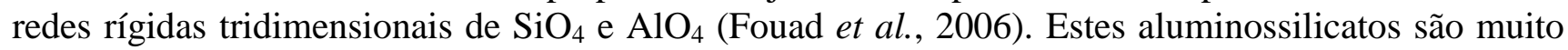
importantes comercialmente, principalmente pela ampla aplicação na indústria petroquímica, com a conversão de hidrocarbonetos (Chauhan et al., 2012). Atualmente, por suas propriedades ácidas e estrutura cataliticamente favoráveis vem sendo foco nos estudos da conversão de álcoois em olefinas leves, como eteno e propeno (Song et al., 2013; Furumoto et al., 2011).

Para sintetizar a ZSM-5 são necessárias fontes de silício e alumínio na presença de um metal alcalino, sendo este último necessário para o balanceamento eletrônico pela presença de alumínio na rede. Além destes, utiliza-se um direcionador de estrutura que são compostos orgânicos em torno dos quais se organizam os tetraedros de silício-oxigênio-alumínio para a formação da estrutura específica, além de serem decisivos na qualidade e propriedades físico-químicas da zeólita. Para esta função, geralmente são utilizados compostos orgânicos nitrogenados como n-butialamina, etilamina e tetrapropilamônio (Sang et al., 2004). Com vistas a se substituir estes compostos orgânicos nitrogenados de elevado custo e toxicidade, estudos que empregam codirecionadores e sementes têm sido desenvolvidos (Calsavara et al., 2000; Lam et al., 1986). 
Os codirecionadores de estrutura são geralmente álcoois de baixo peso molecular, como o álcool etílico, utilizados juntamente com um direcionador a fim de reduzir a quantidade necessária deste, que normalmente é um composto de maior complexidade e custo, e melhorar a qualidade da zeólita (Lam, 1985). Enquanto o emprego de sementes consiste em adicionar à mistura reacional cristais de ZSM-5 previamente sintetizados, de forma isolada ou juntamente com codirecionadores, dispensando o uso dos direcionadores orgânicos (Mendonça et al., 2013).

No presente trabalho propõe-se a síntese da zeólita tipo ZSM-5 na ausência de direcionadores orgânicos nitrogenados, empregando-se sementes e etanol de forma isolada e combinada. Os efeitos do uso de etanol e semente, e da combinação destes com diferentes quantidades de sementes foram avaliados no âmbito das propriedades físico-químicas da estrutura formada, como cristalinidade, área superficial específica e volume de poros.

\section{MATERIAIS E MÉTODOS}

A síntese da ZSM-5 foi realizada através do método hidrotérmico, tendo caulim como fonte de silício e alumínio, hidróxido de sódio como fonte de sódio e cinza da casca de arroz (CCA) como fonte adicional de silício, além de sementes e etanol. A ZSM-5 empregada como semente, amostra B01, foi previamente sintetizada pelo mesmo método, porém utilizando-se n-butilamina como agente direcionador de estrutura e sílica comercial do tipo fumê (Aldrich) como fonte adicional de silício. As condições de síntese estão sumarizadas na Tabela 1.

$\mathrm{Na}$ mistura reacional as razões $\mathrm{SiO}_{2} / \mathrm{Al}_{2} \mathrm{O}_{3}, \mathrm{NaOH} / \mathrm{SiO}_{2}, \mathrm{H}_{2} \mathrm{O} / \mathrm{SiO}_{2}$ e etanol/SiO , foram mantidas constantes e iguais a 40;0,18; 40 e 0,36. A quantidade de sementes adicionada foi variada de 0,1 a $1 \%$ em relação à massa de sílica.

Tabela 1 - Condições empregadas nas sínteses das ZSM-5.

\begin{tabular}{|c|c|c|c|}
\hline Amostra & Fonte de Sílica & $\begin{array}{c}\text { Agente direcionador / } \\
\text { codirecionador }\end{array}$ & $\begin{array}{c}\text { \% semente (em } \\
\text { massa de sílica) }\end{array}$ \\
\hline B01 & Comercial tipo Fumê & n-butilamina & - \\
\hline B02 & CCA & n-butilamina & - \\
\hline S01 & CCA & sementes & 1,0 \\
\hline E01 & CCA & etanol & - \\
\hline ES01 & CCA & etanol + sementes & 1,0 \\
\hline ES02 & CCA & etanol + sementes & 0,1 \\
\hline
\end{tabular}

O procedimento de síntese consistiu em primeiramente dissolver a fonte de alumínio, juntamente com o agente direcionador ou com o agente codirecionador, em uma solução aquosa de hidróxido de sódio, por 30 minutos sob agitação. Em seguida, a fonte de silício já dissolvida na quantidade restante de água era adicionada a mistura anterior, mantendo-a sob agitação por mais 30 
minutos. Finalmente, a mistura era transferida para a autoclave de aço Inox com copo de Teflon de $170 \mathrm{~mL}$, para posterior cristalização a $175^{\circ} \mathrm{C}$ por 24 horas. Decorrido o tempo, a amostra era filtrada, seca e calcinada em mufla a $550^{\circ} \mathrm{C}$ por 6 horas.

A cristalinidade relativa das amostras foi obtida fazendo-se a razão das áreas sob os picos de difração selecionados, entre 7,5 e $9,5^{\circ}$ e entre 22,5 e $24,5^{\circ}$, sendo tomada como referência a amostra com a maior área. $\mathrm{O}$ tamanho médio dos cristalitos foi calculado pela Equação de Scherrer.

As amostras foram caracterizadas por difração de Raio-X, Rigaku modelo Miniflex, com fonte de $30 \mathrm{kV}$ e $10 \mathrm{~mA}$, entre $5,0^{\circ}$ e $50,0^{\circ}$ com passo de $0,02^{\circ}$ por $0,3 \mathrm{~s}$. As propriedades texturais foram determinadas pela técnica de adsorção e dessorção estática de $\mathrm{N}_{2}$ a $77 \mathrm{~K}$, ASAP 2020 (Micromeritics). Espectros de absorção na região do infravermelho foram obtidos na região entre 400 e $4000 \mathrm{~cm}^{-1}$ em espectrômetro FTIR Shimadzu UVPC 2401.

\section{RESULTADOS E DISCUSSÕES}

A amostra B01, empregada como semente nas sínteses das amostras S01, ES01 e ES02, foi sintetizada com n-butilamina como direcionador de estrutura, seu difratograma é apresentado na Figura 1. Observa-se que os planos de difração característicos da estrutura da ZSM-5 estão presentes (valores de $2 \theta$ em torno de $7,85^{\circ}, 8,75^{\circ}, 22,9^{\circ}$ e $23,5^{\circ}$ ), confirmando a formação da estrutura zeolítica da amostra B01, empregada como semente para as demais sínteses. Somado a isso, vê-se que esta amostra apresenta maior cristalinidade relativa, Tabela 2, que a amostra B02 sintetizada com sílica obtida da cinza de casca de arroz. Estes resultados justificam a escolha da amostra sintetizada com sílica fumê como semente para as sínteses posteriores.

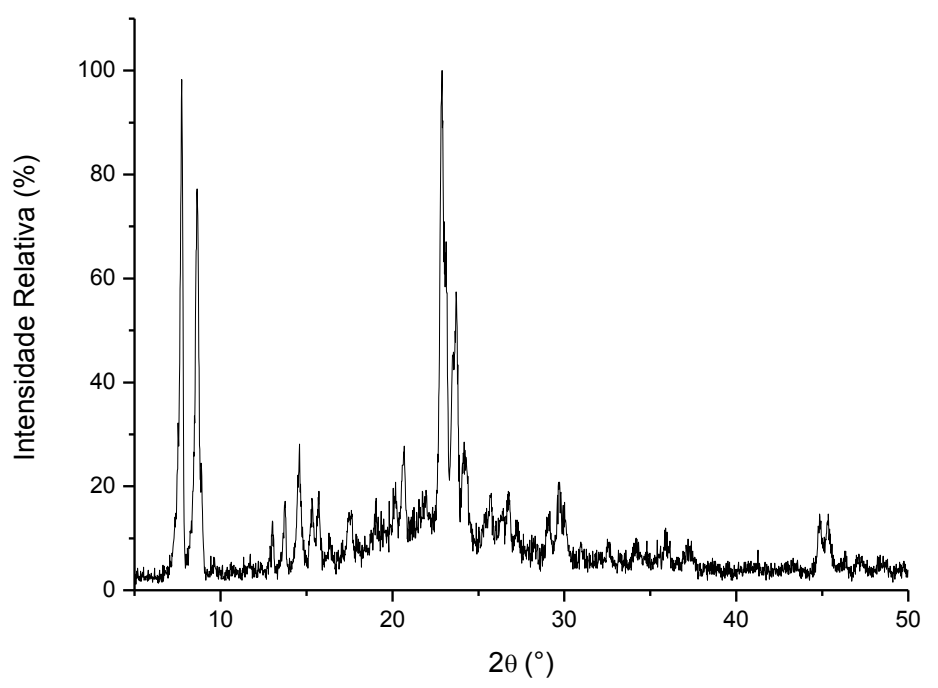

Figura 1 - Difratograma de raios-X da amostra B01.

A partir das análises de difração de raios-X, Figura 2, foi possível calcular a cristalinidade 
relativa entre as amostras e o tamanho médio de cristalito, Tabela 2. Observa-se a partir dos dados de cristalinidade das amostras que o emprego de etanol de forma combinada com sementes resultou em estruturas de alta cristalinidade, inclusive superiores às obtidas com o uso de n-butilamina, sendo a amostra ES01 a mais cristalina. Em contrapartida, as sementes, amostra S01, quando utilizadas de forma isolada geraram uma estrutura de baixa cristalinidade, assim como o uso de etanol sozinho, amostra E01, não foi suficiente para a formação da zeólita, como pode ser visualizado nos difratogramas de raios-X apresentados na Figura 2.

Tabela 2 - Propriedades físico-químicas das amostras de zeólita ZSM-5.

\begin{tabular}{|c|c|c|c|c|c|}
\hline Amostra & $\begin{array}{l}\text { Cristalinidade } \\
\text { Relativa }(\%)\end{array}$ & $\begin{array}{c}\text { Tamanho } \\
\text { médio } \\
\text { cristalitos }(\AA)\end{array}$ & $\begin{array}{c}\text { Área BET } \\
\left(\mathbf{m}^{2} / \mathbf{g}\right)\end{array}$ & $\begin{array}{c}\text { Volume } \\
\text { microporos } \\
\left(\mathrm{cm}^{3} / \mathrm{g}\right)\end{array}$ & $\begin{array}{c}\text { Volume } \\
\text { mesoporos } \\
\left(\mathrm{cm}^{3} / \mathrm{g}\right)\end{array}$ \\
\hline B01 & 78,85 & 184,1 & 198,9 & 0,044 & 0,073 \\
\hline B02 & 68,63 & 208,8 & 226,0 & 0,050 & 0,083 \\
\hline S01 & 55,46 & 208,8 & 77,2 & 0,025 & 0,033 \\
\hline ES01 & 100,00 & 208,9 & 271,0 & 0,084 & 0,057 \\
\hline ES02 & 66,73 & 208,8 & 131,5 & 0,042 & 0,027 \\
\hline
\end{tabular}

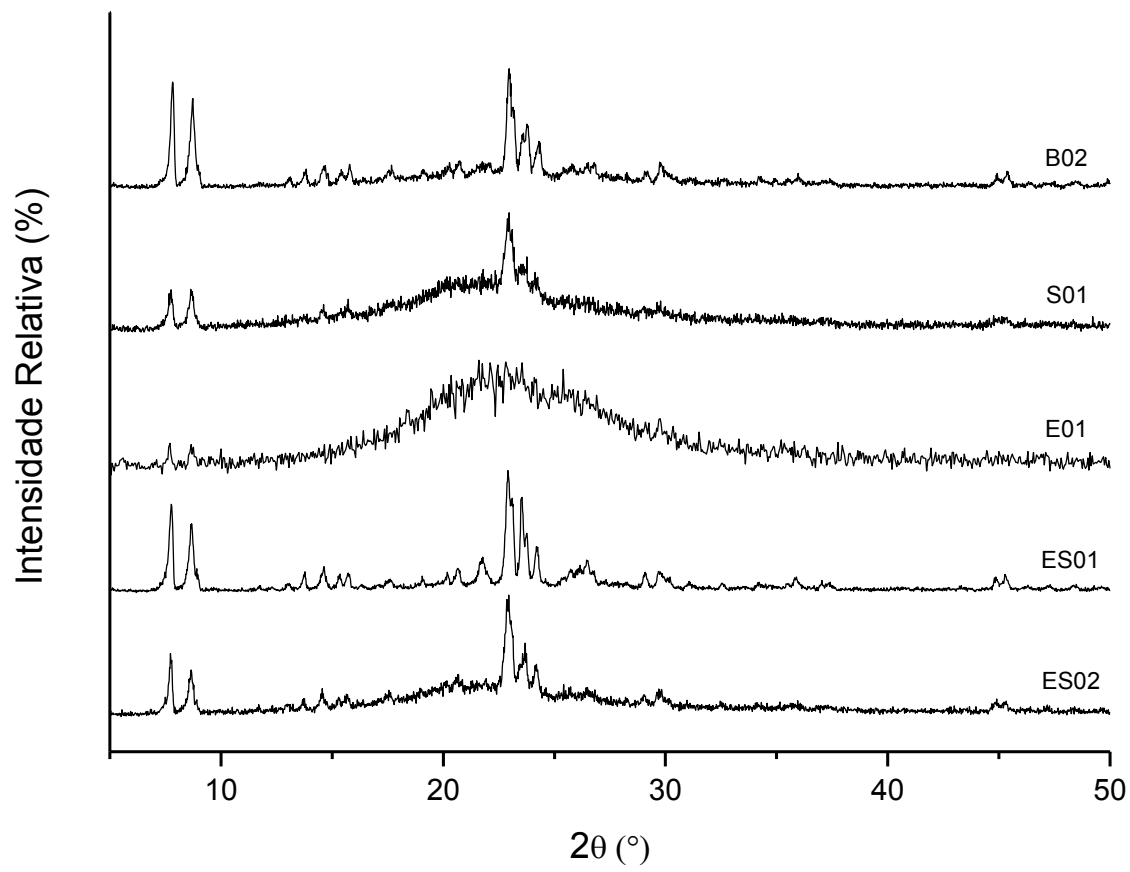

Figura 2 - Difratogramas de raios- $X$.

As isotermas de adsorção de $\mathrm{N}_{2}$ a 77K das amostras ES01 e B02 são apresentadas na Figura 3. Segundo classificação IUPAC, a amostra B02 apresenta a isoterma de adsorção que pode ser 
identificada como do tipo IV, característico de sólidos contendo microporos associados à macroporos. Já a amostra ES01, apresenta isoterma de adsorção com o início, referente a baixos valores de pressões relativas, como sendo do tipo IV, porém na sua parte final, referente a pressões relativas mais altas, apresenta semelhança com as isotermas do tipo III, característica de sólidos não porosos associados à mesoporos. É possível notar ainda a histerese do tipo II, para ambas as amostras, atribuída ao fenômeno de condensação capilar que ocorre em estruturas mesoporosas (Sing, 1982). As isotermas de adsorção das demais amostras apresentaram as mesmas características da amostra ES01.
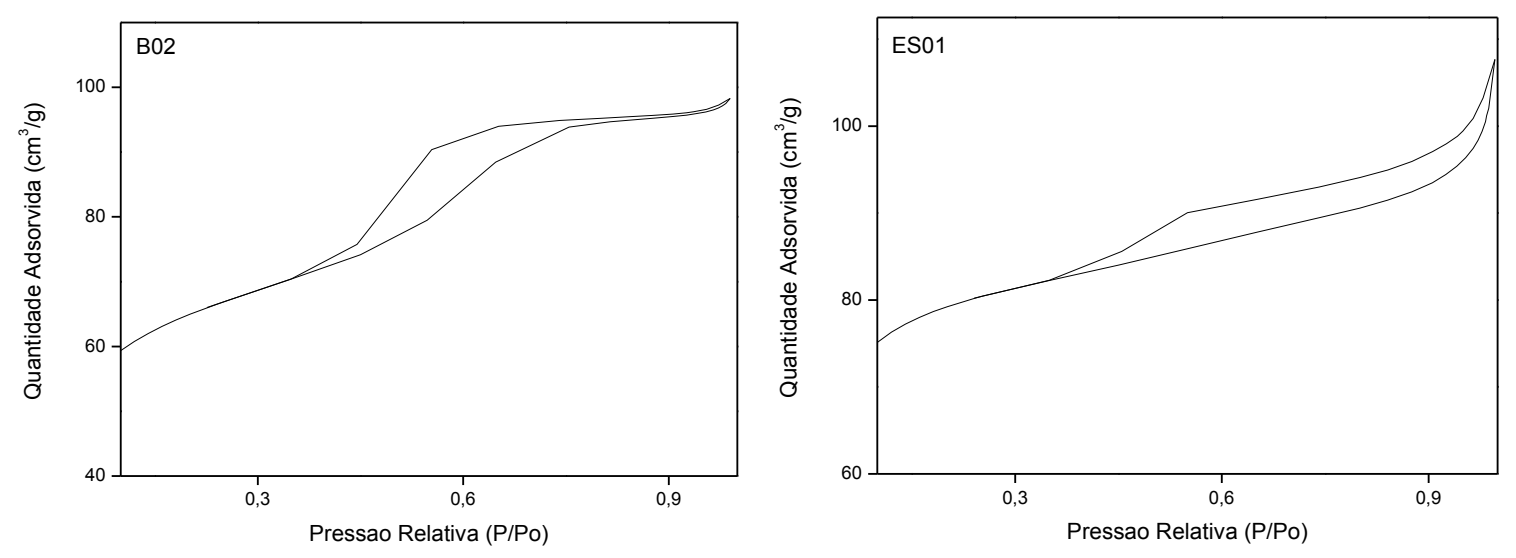

Figura 3 - Isotermas de adsorção de $\mathrm{N}_{2}$ das amostras B02 e ES01.

As análises texturais, Tabela 2, confirmam a eficiência conjunta de etanol e sementes na obtenção de estruturas cristalinas de elevada superfície específica. A área específica da amostra sintetizada com $1 \%$ de sementes foi a maior obtida, estando de acordo com os valores encontrados na literatura (Foud et al., 2006; Sang et al., 2004; Calsavara et al., 2000). Nota-se que esta amostra é também a amostra de maior cristalinidade relativa, o que indica que a superfície específica tanto é maior quanto mais cristalina é a estrutura. As demais amostras apresentaram área específica inferior devido a menor cristalinidade, principalmente a amostra S01, sintetizada com sementes na ausência de etanol, devido à presença de material amorfo. Pode-se verificar ainda, que o emprego de sementes na quantidade de $1 \%$ leva a um aumento no volume de microporos na estrutura e a redução do volume de mesoporos, quando comparado com a amostra B01, sintetizada com direcionador de estrutura.

Os espectros de infravermelho das amostras de ZSM-5 são mostrados na Figura 4. Todas as amostras apresentaram espectros característicos da ZSM-5, com bandas em torno de $450 \mathrm{~cm}^{-1}$, devido aos estiramentos $\mathrm{Si}-\mathrm{O}$ e Al-O, em $550 \mathrm{~cm}^{-1}$, característico do anel duplo de cinco membros, próximo de $795 \mathrm{~cm}^{-1}$, atribuído ao estiramento simétrico externo, e em torno de $1100 \mathrm{~cm}^{-1}$, banda característica das vibrações assimétricas internas aos tetraedros Si-O-Al (Colpo, 2013; Mohamed et al., 2005; 2008; Kulkarni et al., 1982). As bandas reduzidas em torno de $550 \mathrm{~cm}^{-1}$ se devem a presença de impurezas nas amostras (Calsavara et al., 2000). 


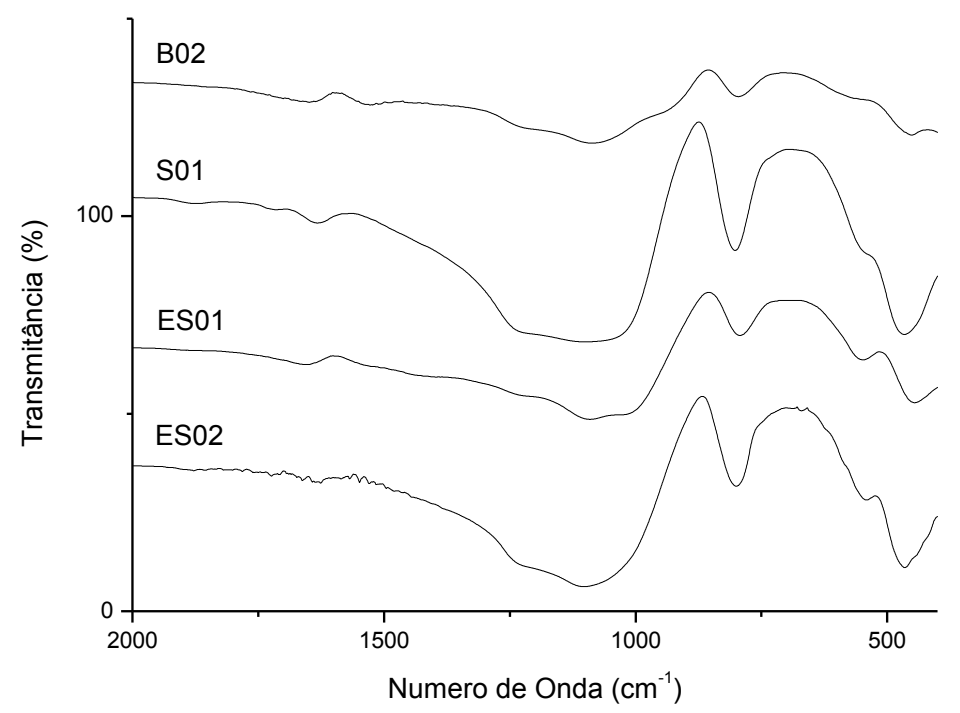

Figura 4 - Espectros de infravermelho das amostras de zeólita ZSM-5.

\section{CONCLUSÕES}

Neste trabalho, estudaram-se diferentes metodologias de síntese para a zeólita do tipo ZSM-5, buscando a substituição dos usuais direcionadores de estrutura por etanol e sementes. O emprego de sementes combinadamente com etanol foi excelente para a formação da estrutura zeolítica com alta cristalinidade e área superficial condizente com as encontradas na literatura. Enquanto que com o emprego de etanol sozinho a estrutura cristalina não foi obtida e com o emprego das sementes isoladamente se obteve estrutura de baixa cristalinidade e reduzida área específica, pela formação de material amorfo. Portanto, etanol e sementes combinadamente podem substituir de forma satisfatória os direcionadores orgânicos nitrogenados na síntese de ZSM-5.

\section{REFERÊNCIAS}

CALSAVARA, V.; YOSHIDA, C. K. C.; CARDOSO, H. D. P.; MACHADO, N. R. C. F. Estudo da metodologia de síntese de zeólitas ZSM-5. Acta Scientiarum, v. 22, p. 1179-1184, 2000.

CHAUHAN, N. L.; DAS, J.; JASRA, R. V.; PARIKH, P. A.; MURTHY, Z.V.P. Synthesis of small-sized ZSM-5 zeolites employing mixed structure directing agents. Mater. Lett., v. 74, p. 115-117, 2012.

COLPO, D. P. Síntese e caracterização de catalisadores de SM-5 e SAPO-34 para conversão de etanol em olefinas leves. Dissertação de Mestrado, UFSM, 2013.

FOUAD, O. A.; MOHAMED, R. M.; HASSAN, M. S.; IBRAHIM, I. A. Effect of template type and template/silica mole ratio on the crystallinity of synthesized nanosized ZSM-5. Catal. Today, v. 116, p. 82-87, 2006. 
FURUMOTO, Y.; HARADA, Y.; TSUNOJI, N.; TAKAHASHI, A.; FUJITANI, T.; IDE, Y.; SADAKANE, M.; SANO, T. Effect of acidity of ZSM-5 zeolite on conversion of ethanol to propylene. Appl. Catal. A: General, v. 399, p. 262-267, 2011.

KULKARNI, S. B.; SHIRALKAR, V. P.; KOTASTHANE, A. N.; BORADE, R. B.; RATNASAMY, P. Studies in the synthesis of ZSM-5 zeolites. Zeolites, v. 2, p. 313-318, 1982.

LAM, Y. L. Processo de preparação de zeólito tipo ZSM-5. Patente Brasileira PI8506248, 1985.

LAM, Y. L.; NOGUEIRA, L.; FERNANDEZ, S. C. Processo de preparação de zeólito sintético com estrutura tipo ZSM-5. Patente Brasileira PI8606367, 1986.

MENDONÇA, T. R. D.; SILVA, A. O. S.; NETO, P. P. M.; OLIVEIRA, L. M. R.; SILVA, D. C. M.; URBINA, M. M. Síntese e caracterização da zeólita ZSM-5 com adição de sementes, utilizando diferentes fontes de sílica. Anais do $17^{\circ}$ CBCat, 2013.

MOHAMED, R. M.; ALY, H. M.; EL-SHAHAT, M. F.; IBRAHIM, I. A. Effect of the silica sources on the crystallinity of nanosized ZSM-5 zeolite. Micropor. Mesopor. Mat., v. 79, p. 7-12, 2005.

MOHAMED, M. M.; ZIDAN, F. I.; THABET, M. Synthesis of ZSM-5 zeolite from rice husk ash: Characterization and implications for photocatalytic degradation catalysts. Micropor. Mesopor. Mat., v. 108, p. 193-203, 2008.

SANG, S.; CHANG, F.; LIU, Z.; HE, C.; HE, Y.; XU, L. Difference of ZSM-5 zeolites synthesized with various templates. Catal. Today, v. 93-95, p. 729-734, 2009.

SING, K. S. W. Reporting physisorption data for gas/solid systems with special reference to the determination of surface area and porosity. Pure Appl. Chem., v. 54, n. 11, p. 2201 - 2218, 1982.

SONG, Z.; LIU, W.; CHEN, C.; TAKAHASHI, A.; FUJITANI, T. Production of propylene from ethanol over ZSM-5 co-modified with zirconium and phosphorus. Reac. Kinet. Mech. Cat., v. 109, p. 221-231, 2013. 